\title{
A Study of the Effect of Zataria multiflora Extract on Methicillin Resistant Staphylococcus aureus
}

\author{
Maryam Motevasel ${ }^{1, *}$, Mohammad Ali Okhovat $^{2}$, Kamiar Zomorodian $^{3}$, Shohreh Farshad $^{4}$ \\ ${ }^{1}$ Diagnostic Laboratory Sciences and Technology Research Center, Faculty of Paramedical Sciences, Shiraz University of Medical Sciences, Shiraz, IR Iran \\ 2 Student Research Committee, Shiraz University of Medical Sciences, Shiraz, IR Iran \\ 3 Department of Mycology, Medical Faculty, Shiraz University of Medical Sciences, Shiraz, IR Iran. \\ 4 Department of Mycology, Medical Faculty, Shiraz University of Medical Sciences, Shiraz, IR Iran.
Professor Alborzi Clinical Microbiology Research Center, Shiraz University of Medical Sciences, Shiraz, IR Iran \\ ${ }^{*}$ Corresponding author: Maryam Motevasel, Faculty of Paramedical Sciences, Meshkinfam Street, Shiraz University of Medical Sciences, Shiraz, IR Iran. Tel.: +98-7112289113, Fax: +98- \\ 7112289113, E-mail: maryam.motevasel@ymail.com.
}

Received: May 14, 2012; Revised: July 22, 2012; Accepted: July 28, 2012

\begin{abstract}
Background: One of the most common nasocomial bacteria is methicillin resistant Staphylococcus aureus (MRSA). Today, herbal extracts like Zataria multiflora from the Lamiaceae family are increasingly used.

Objectives: In this study, the antibacterial effect of Z. multiflora on 75 strains of was evaluated.

Materials and Methods: The strains of Staphylococcus aureus were examined for isolation of strains. 75 out of 232 strains were diagnosed as by oxacillin $6 \mu \mathrm{g} / \mathrm{mL}$ screening method. The extracts of $Z$. multiflora were prepared from dried leaves using a maceration method. The antibacterial activity of the extract with initial concentration of $200 \mu \mathrm{g} / \mathrm{mL}$ was determined by the micro broth dilution method.

Results: The obtained results showed that the minimum inhibitory concentration (MIC) varied from 2 to $16 \mu \mathrm{g} / \mathrm{mL}$ for strains. It inhibited the growth of S. epidermidis, S. saprophyticus and methicillin sensitive S. aureus (MSSA) by about 8 $-16 \mu \mathrm{g} / \mathrm{mL}$. The minimum bactericidal concentration (MBC) of the extract that could destroy 62.2\% strains and the other examined bacteria was $512 \mu \mathrm{g} / \mathrm{mL}$ or more.

Conclusions: In conclusion, it seems that $Z$. multiflora extracts could inhibit the growth of all of the mentioned bacteria. We noticed that the bactericidal effect of $Z$. multiflora extracts was less than its bacteriostatic effects.
\end{abstract}

Keywords: Nasocomial Bacteria; Zataria multiflora; Methicillin Resistant; Staphylococcus aureus

\section{Background}

Staphylococcus aureus (S. aureus) is one of the most common nosocomial bacteria of infectious diseases such as endocarditis, osteomyelitis and food poisoning (1). With the spread of $\beta$-lactam resistant $S$. aureus, methicillin was synthesized from penicillin. Very soon methicillinresistant S. aureus strains were identified. Methicillinresistant S. aureus (MRSA) is one of the major nosocomial bacteria that leads to epidemiologic and clinical disorders. This organism can be transmitted among hospital personnel and hospitalized patients. In addition, MRSA has many virulence factors that create serious risks in sick or healthy individuals (2). In New York City hospitals, MRSA accounts for $29 \%$ of nosocomial infections and $50 \%$ of associated deaths (3). The replacement of antibacterial agents with herbal medicines may overcome the above- mentioned resistant bacteria.

One of these treatment modalities is Zataria multiflora, referred as "Avishen-e-Shirazi" in Persian, which is a very famous Iranian folk medicine. Z. multiflora is a member of the Lamiacea family and the most effective compounds in this medication are Thymol and Caracrol which have antibacterial effects (4). This plant grows in the south of Iran, Pakistan, India, and Afghanistan. The dried leaves of the plant were used in the food industry as a preservative and also for its flavor (5). The extracts stimulate innate immunity (6) and inhibit the growth organisms such as fungi and bacteria (4).

\section{Objectives}

In this study, we investigated the effects of alcoholic $Z$. multiflora extracts on 75 clinical MRSA isolates from pa- 
tients in Faghihi Hospital (Shiraz University of Medical Sciences, Iran) during 2010-2012.

\section{Materials and Methods}

\subsection{MRSA Isolation}

The cultured samples were from wounds, abscesses, ears, nose, blood cultures and groins. 232 S. aureus strains were isolated from patients in Faghihi Hospital (Shiraz University Of Medical Sciences, Iran). We diagnosed $S$. aureus by the tube coagulase test, DNase test and growth in mannitol salt agar from mentioned specimens (2). For isolating MRSA, we used "a plate containing $6 \mu \mathrm{g} / \mathrm{mL}$ of oxacillin in Mueller Hinton Agar supplemented with $\mathrm{NaCl}(4 \% \mathrm{w} / \mathrm{v} ; 0.68 \mathrm{~mol} / \mathrm{L}) "$ (7). After culturing the specimens, 75 strains were diagnosed as MRSA from the mentioned bacteria.

\subsection{Extract Preparation}

Maceration method was used to prepare Zataria extracts (8). First, some dried leaves of $Z$. multiflora were ground. Next, this was mixed with $80 \%$ ethanol and kept in a dark bottle. After $48 \mathrm{~h}$ of incubation in a dark room, it was filtered. It was then totally concentrated by the Rotary evaporator (Heidolph, Germany) and the alcohol-free extract was obtained. The extract was then frozen at $25^{\circ} \mathrm{C}$ and finally the frozen extract was powdered by the freeze dryer (Zerbus, Germany).

\subsection{Determination of Antimicrobial Activities of the Extract Against MRSA}

The antibacterial activities of the extract against 75 clinical isolates of bacteria were determined by standard methods (2). Disk diffusion agar method was used to examine the susceptibility of all clinical isolates of the bacteria against selected antibiotics (9). Some of them were resistant and the others were sensitive to the current antibiotics.

\subsection{Determination of Minimum Inhibitory Concen- tration (MIC) of the Extract Against MRSA}

MICs were determined by using the broth micro dilution method recommended by the CLSI protocol with some modifications (9). To determine the antimicrobial activities of Zataria extracts against the bacteria, the initial concentration of the extract was prepared with 200 $\mu \mathrm{g} / \mathrm{mL}$ in Dimethyl Sulfoxide (DMSO) as the solvent (Merck, Germany). Next, serial dilutions of the extract from the $2-512 \mu \mathrm{g} / \mathrm{mL}$ suspension were prepared in 96-well micro titer plates (Sigma, USA), using Muller Hinton broth
(Merck, Germany).

The bacterial suspension was adjusted to 0.5 McFarland standards and then diluted to 1:1000 (10).100 micro liters of the bacterial suspension in $1.5 \times 10^{5} \mathrm{cfu} / \mathrm{mL}$ concentration was added to each well except the negative control and the initial concentration of the extract. The cultured micro plate was incubated at $35^{\circ} \mathrm{C}$ for 18 hours. After 24 hours of incubation, the tests were studied. The components of the positive control well included media, bacterial suspension and maximum concentration of the solvent. There were media and solvent in the negative control well. After incubation, the micro titer plates were studied. Wells without sediments indicated no growth of bacteria. The first well, which showed no growth, was considered as the MIC.

\subsection{Determination of Minimum Bactericidal Con- centration (MBC) of the Extract Against MRSA}

10 micro liters of MIC of the extract and the previous concentrations were sub cultured via the spotted form on Muller Hinton Agar (MHA) (Merck, Germany) for determination of MBC. All of the inoculated plates were incubated at $35^{\circ} \mathrm{C}$ for 18 hours. The first spotted culture on MHA, which showed no growth, was considered as the MBC.

\section{Results}

As Table 1 shows, MIC and MBC were measured for MRSA and MSSA. The alcoholic extract of Avishen-e-Shirazi inhibited the growth of all of the MRSA strains in the range of 2 to $16 \mu \mathrm{g} / \mathrm{mL}$. Also, it inhibited the growth of S. aureus, $S$. epidermidis, S. saprophyticus and ATCC 25923 strain of $S$. aureus by $8-16 \mu \mathrm{g} / \mathrm{mL}$. The MBC of the extract that could destroy all of the examined bacteria was $512 \mu \mathrm{g} / \mathrm{mL}$ or more. 47 isolates $(62.2 \%)$ of MRSA were killed with this extract.

\section{Discussion}

Nowadays, the drug resistant bacteria can create the most important infectious diseases. One aspect of such problem is the incidence of multidrug resistant bacteria like MRSA in hospitals. For resolving this problem, many investigators noticed the effect of herbal extracts instead of antibiotics $(4,5)$. Based on the previous studies, the $A v$ ishen-e-Shirazi extract can inhibit the growth of enterohemorrhagic Escherichia coli (11), Salmonella sp and Shigella sp (12), S. aureus (13), Klebsiella (14), Enterococcus (15), Pseudomonas aeruginosa (16), and Acinetobacter baumannii, Alcaligenes, Chryseobacterium meningosepticum in the NFB (Non Fermentative Gram Negative Bacteria ) group.(13). 
Table 1. The Comparison of MIC and MBC $(\mu \mathrm{g} / \mathrm{mL})$ of Alcohol Extracts of Z . multiflora on MRSA

\begin{tabular}{lll}
\hline Bacteria (No.) & MIC $^{\mathrm{a}}, \boldsymbol{\mu g} / \mathbf{m L}$ (No.) & $\mathbf{M B C}^{\mathrm{a}}, \boldsymbol{\mu g} / \mathbf{m L}, \mathbf{N o .}$ \\
\hline & $2(5)$ & $2(0)$ \\
& $4(12)$ & $4(0)$ \\
& $8(30)$ & $8(0)$ \\
S. aureus (MRSA) (75) & $16(28)$ & $16(3)$ \\
& $32(0)$ & $32(13)$ \\
& $64(0)$ & $64(6)$ \\
S. aureus (ATCC25923) & $128(0)$ & $128(7)$ \\
S. aureus (MSSA) & $256(0)$ & $256(10)$ \\
S. epidermidis (1) & $512(0)$ & $512(7)$ \\
S. saprophyticus & $16(1)$ & $512(1)$ \\
\hline
\end{tabular}

a Abbreviations: MIC, Minimum Inhibitory Concentration; MBC, Minimum Bactericidal Concentration; MRSA, Methicillin Resistant Staphylococcus aureus

In this study the effect of alcoholic Z. multiflora extract on MRSA was studied. Based on the obtained results, we found that the micro broth dilution method is more sensitive than tube macro broth dilution and disk agar diffusion as used by previous investigators (14). Moreover, we noticed that the alcoholic Zataria extracts could inhibit the growth of MRSA strains and kill 62.2\%. The extract could also inhibit the growth of MSSA, ATCC 25923 of S. aureus, S. epidermidis and S. saprophyticus as well as MRSA. There were no differences between the mentioned bacteria due to inhibitory and bactericidal effects of the extract.This research shows that low concentrations of Zataria extracts inhibit the growth of MRSA efficiently. The results have shown that the inhibitory effect of the extract is better than its bactericidal effect on the mentioned bacteria. Due to the oral intake of Z. multiflora, we suggest that the high concentration of the extract could be administered for prevention of bacterial growth. We also suggest some experiments to be performed using the extracts in the form of lotions or creams on skin, cutaneous and subcutaneous lesions on lab animals in order to cure or prevent staphylococcal lesions.

\section{Acknowledgements}

We gratefully acknowledge Dr. Nasrin Shokrpour for her assistance in editing the text.

\section{Authors' Contribution:}

None declared.

\section{Financial Disclosure:}

All authors declare that they have no conflict of interest.

\section{Funding/Support:}

This research has been supported by the grant of Shiraz University of Medical Sciences \& Health Services.

\section{References}

1. Classics in infectious diseases. "On abscesses". Alexander Ogston (1844-1929). Rev Infect Dis. 1984;6(1):122-8.

2. Winn Washington C, Allen Stephen D, Janda William M, Koneman Elmer W, Schreckenberger Paul C, Procop Gary W, et al. Koneman's color atlas and textbook of diagnostic microbiology. 2005.

3. Rubin RJ, Harrington CA, Poon A, Dietrich K, Greene JA, Moiduddin A. The economic impact of Staphylococcus aureus infection in New York City hospitals. Emerg Infect Dis. 1999;5(1):9-17.

4. Shafiee A, Javidnia K. Composition of essential oil of Zataria multiflora. Planta Med.1997;63(4):371-2.

5. Gandomi H, Misaghi A, Basti AA, Bokaei S, Khosravi A, Abbasifar A, et al. Effect of Zataria multiflora Boiss. essential oil on growth and aflatoxin formation by Aspergillus flavus in culture media and cheese. Food Chem Toxicol. 2009;47(10):2397-400.

6. Soltani M, Sheikhzadeh N, Ebrahimzadeh-Mousavi HA, Zargar A. Effects of Zataria multiflora Essential Oil on Innate Immune Responses of Common Carp (Cyprinus carpio). J Fish Aqua Sci. 2010;5:191-9.

7. Laboratory Detection of Oxacillin/Methicillin-resistant Staphylococcus aureus. 2005; Available from: http://www.cdc.gov/mrsa/ lab/lab-detection.html.

8. Gennaro AR. Remington's pharmaceutical sciences. 1990.

9. Methods for Dilution Antimicrobial Susceptibility Tests for Bacteria that Grow Aerobically. Clinical and Laboratory Standards Institute. 2006.

10. Baron EJ, Peterson LR, Finegold SM. Bailey \& Scott's Diagnostic Microbiology. 1990. 
11. Fazlara A, Najafzadeh H, Lak E. The potential application of plant essential oils as natural preservatives against Escherichia coli O157:H7. PakJ Biol Sci. 2008;11(17):2054-61.

12. Shokri H, Asadi F, Bahonar AR, Khosravi AR. The Role of Zataria multiflora Essence (Iranian herb) on Innate Immunity of Animal Model. Iran JImmunol. 2006;3(4):164-8.

13. Motevasel M, Zomorodian K, Ashraf Mansouri MA, Farshad SH, Haghighhat AR, Hadaegh MG, et al. The anti-bacterial effects of Zataria multiflora extract on common pathogenic Gram positive cocci, pathogenic Gram negative bacilli and non-pathogenic bacteria. African J Microbiol Res. 2011;5(28):4993-4996.

14. Abbasgholizadeh N, Ettehad GH, Arab R, Nemati A, Barak M, Pirzadeh A, et al. Antibacterial effects of Zataria multiflora Boiss (Shiraz organo essence) on Enterobacteriaceae species. Res J Biol Sci. 2008;3:345-47.

15. Mir N, Sanchez M, Baquero F, Lopez B, Calderon C, Canton R.
Soft salt-mannitol agar-cloxacillin test: a highly specific bedside screening test for detection of colonization with methicillin-resistant Staphylococcus aureus. J Clin Microbiol. 1998;36(4):986-9.

16. Owlia Parviz, Saderi Horieh, Rasooli Iraj, Sefidkon Fatemeh. Antimicrobial characteristics of some herbal Oils on Pseudomonas aeruginosa with special reference to their chemical compositions. Iran J Pharm Res. 2010;8(2):107-114.

Please cite this paper as: Motevasel M, Okhovat MA, Zomorodian K, Farshad Sh. A Study of the Effect of Zataria multiflora Extract on Methicillin Resistant Staphylococcus aureus. Jundishapur J Microbiol. 2013;6(5): e5453. DOI: 10.5812/jjm.5453. 